Miami Nature Biotechnology Short Reports

TheScientificWorld (2001) 1(S3), 57SR

ISSN 1532-2246; DOI 10.1100/tsw.2001.173

\title{
SECONDARY NECROSIS OF APOPTOTIC NEUTROPHILS CONTRIBUTES TO INFLAMMATORY LUNG INJURY IN VIVO
}

\author{
Djordje Medan ${ }^{1}$, Liying Wang ${ }^{2}$, and Yon Rojanasakul ${ }^{1 *}$ \\ ${ }^{1}$ West Virginia University, Department of Basic Pharmaceutical Sciences, Health Sciences Center, \\ P.O. Box 9530, Morgantown, WV 26506, USA; ${ }^{2}$ National Institute for Occupational Safety and \\ Health, Pathology and Physiology Research Branch, Morgantown, WV 26505, USA \\ *yrojanasakul@hsc.wvu.edu
}

INTRODUCTION. Apoptosis has been suggested as a means to facilitate the resolution of pulmonary inflammation (1), however, uncontrolled apoptosis can also cause pulmonary disease and prolong inflammation (2). The present study investigated the role of apoptosis and its relationship to necrosis during acute pulmonary inflammation caused by lipopolysaccharide (LPS).

METHODS. Balb/c mice were administered with LPS intratracheally and bronchoalveolar lavage (BAL) was performed. Apoptosis was determined by measuring histone-bound DNA fragments using an ELISA kit (Boehringer Mannheim), while necrosis was assessed by measuring cell lysis using lactate dehydrogenase (LDH) assay.

RESULTS. Treatment of mice with LPS causes a time-dependent increase in the number of inflammatory cells in the BAL fluids (Fig. 1). Control mice showed only resident alveolar macrophages with no apoptosis (Fig. 2A). In contrast, LPS-treated mice showed clear apoptosis of BAL cells (Fig. 2A). Microscopic studies confirmed the presence of apoptotic neutrophils and macrophages ingesting apoptotic bodies (result not shown). The number of apoptotic neutrophils increased concomitantly with the increase in neutrophil influx that peaked 1 day after the treatment. However, no necrosis could be detected at this early time point whereas apoptosis continued to increase and peaked at day 2. Necrosis gradually increased by day 2 and reached a maximal level by day 3 where it subsequently declined.

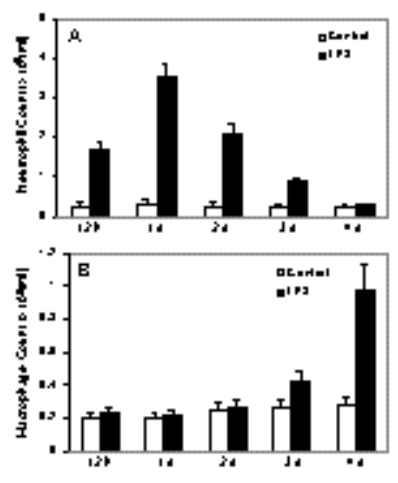


Fig. 1. BAL analysis of LPS-treated mice. Mice were treated with LPS (30 $\mu \mathrm{g})$ or saline and the cell number of neutrophil (A) and macrophage (B) was determined. Data are shown as the mean \pm SEM, $n=4$ mice/group.

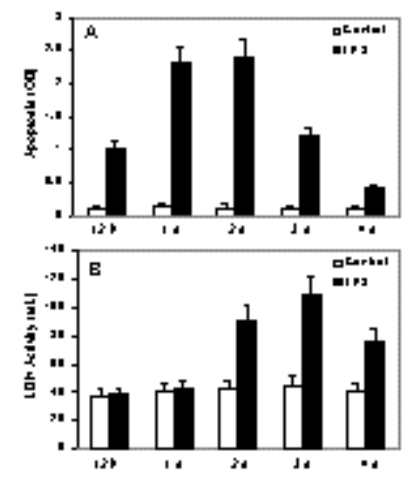

Fig. 2. Time-courses of apoptosis and necrosis. Mice were treated with LPS (30 $\mu \mathrm{g})$ and BAL was analyzed at indicated times. Data are shown as the mean + SEM, $n=4$ mice/group.

DISCUSSION. In the present study, we demonstrated that the initial phase of lung inflammation, i.e., neutrophil influx, was not associated with necrosis but rather with apoptosis. However, necrosis developed subsequently to apoptosis, possibly due to inefficient phagocytic clearance of apoptotic cells. We conclude that the injurious effect of LPS is not a direct insult of this agent on the lung tissue but a consequence of inefficient apoptotic cell clearance that leads to the development of secondary necrosis and subsequent release of toxic contents.

ACKNOWLEDGEMENT. This work was supported by the National Institutes of Health Grant HL62959 (to Y.R.).

\section{REFERENCES.}

1. Cox, G., Crossley, J., and Xing, Z. (1995) Am. J. Respir. Cell Mol. Biol. 12, 232.

2. Hagimoto, N., Kuwano, K., Miyazaki, H., Kunitake, R., Fugita, M., Kawasaki, M., Kaneko, Y., and Hara, N. (1997) Am. J. Respir. Cell Mol. Biol. 17, 271 

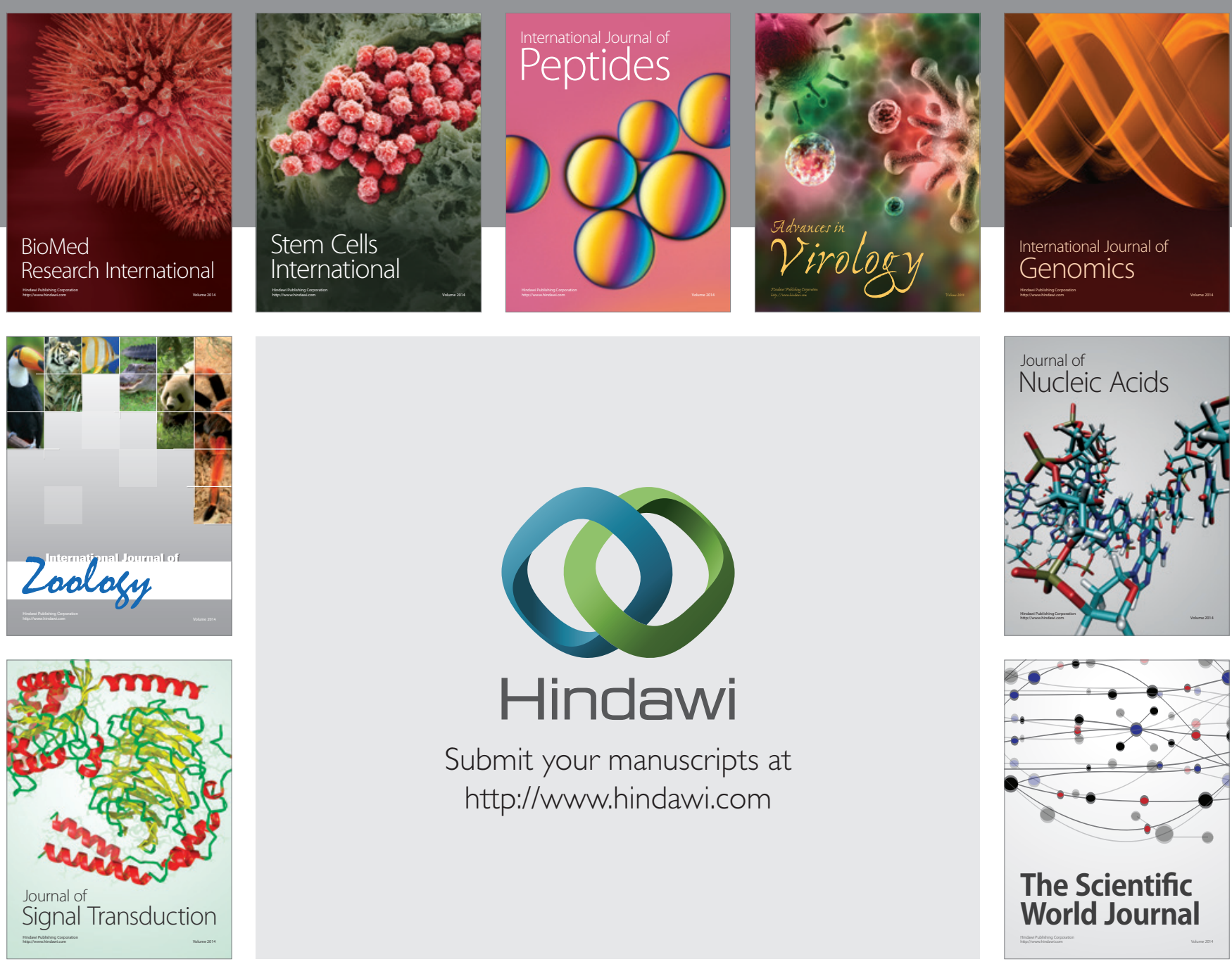

Submit your manuscripts at

http://www.hindawi.com
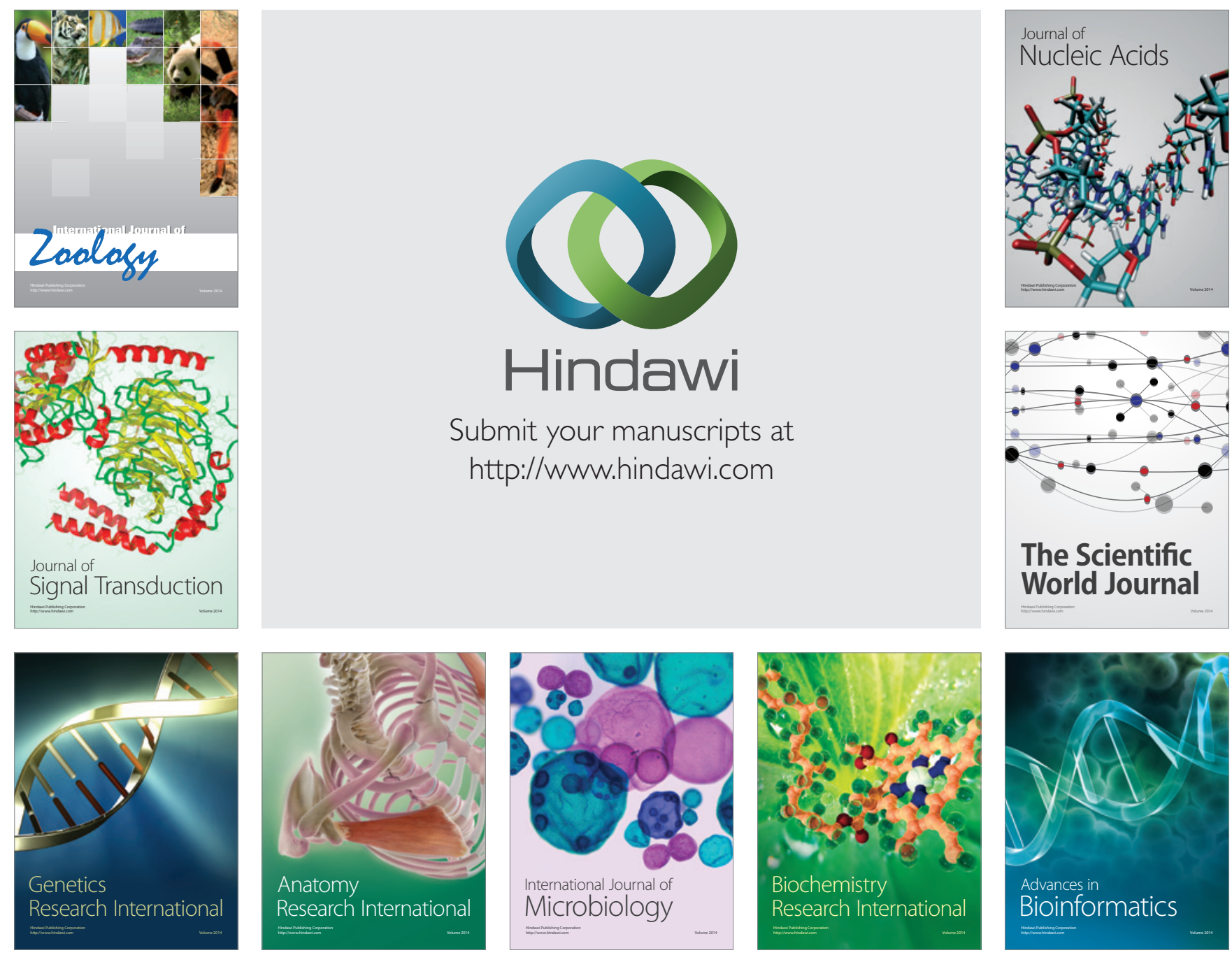

The Scientific World Journal
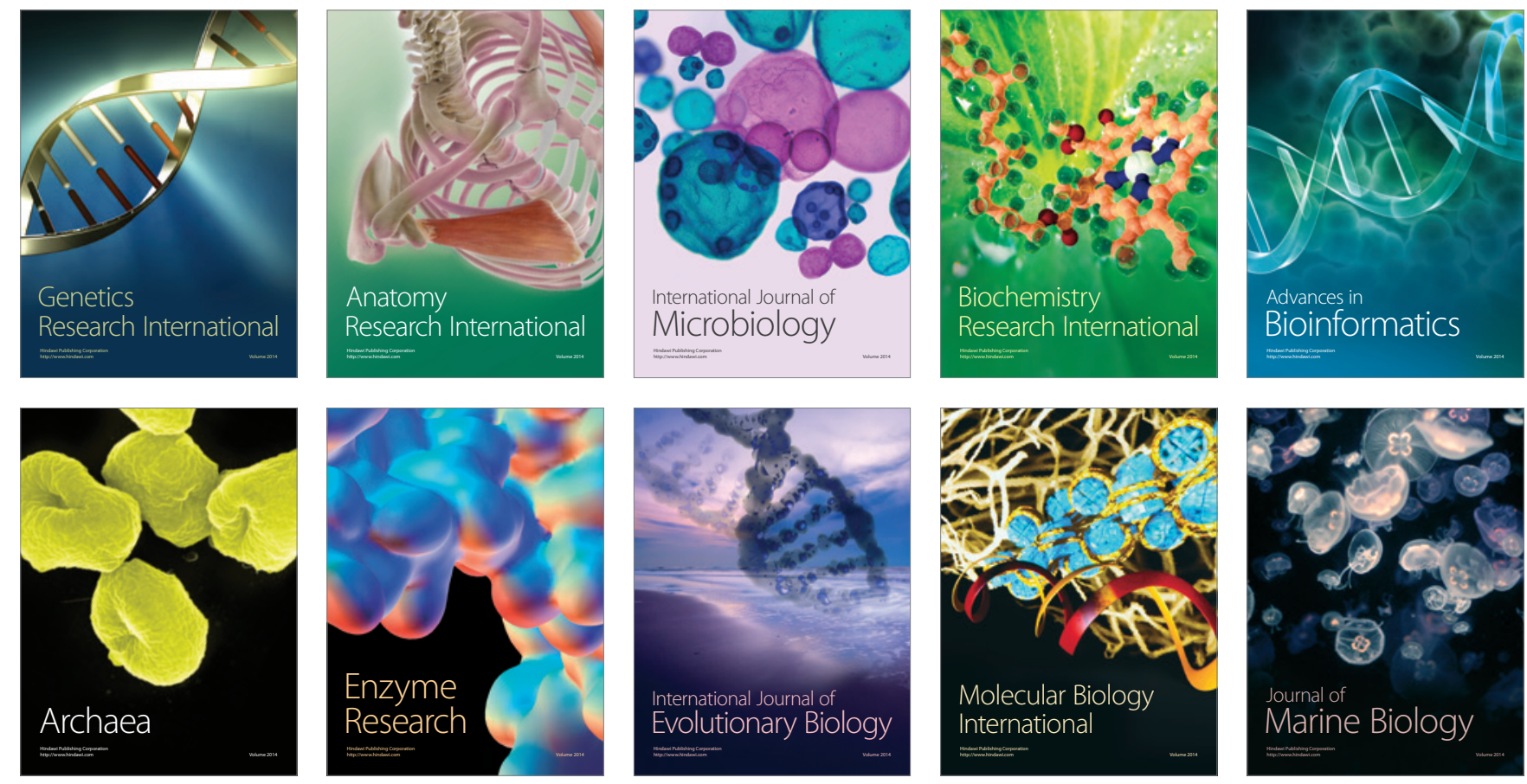